\title{
Phosphate from treated wastewater enhances arsenic release from contaminated stream sediments
}

\author{
PETRA VENHAUEROVA ${ }^{1}$, PETR DRAHOTA $^{2}$, LADISLAV \\ STRNAD $^{3}$ AND ŠÁRKA MATOUŠKOVÁ ${ }^{4}$ \\ ${ }^{1}$ Institute of Geochemistry, Mineralogy and Mineral Resources, \\ Faculty of Science, Charles University \\ ${ }^{2}$ Faculty of Science, Charles University \\ ${ }^{3}$ Charles University \\ ${ }^{4}$ Institute of Geology, Czech Academy of Sciences \\ Presenting Author: petra.venhauerova@natur.cuni.cz
}

Arsenate and phosphate competition represents one of the crucial pathways increasing As concentrations in ground and surface waters. Among an important source of phosphate to freshwater rivers and streams are wastewater treatment plants (WWTP). An effect of long-term ( 7 years) interaction of phosphate released from treated WWTP effluent (75-245 $\mu \mathrm{M}$ $\mathrm{PO}_{4}$ ) with As-rich streambed sediments was studied on a small stream in the central Czech Republic. The arsenic concentration here varied $69-130 \mu \mathrm{g} / \mathrm{l}$ in stream water and $171-236 \mathrm{mg} / \mathrm{kg}$ in sediment. The stream water affected by WWTP discharge attained up to $80 \mu \mathrm{M} \mathrm{PO}_{4}$. In the streambed sediment, arsenic was bound mostly to $\mathrm{Fe}$ (hydr)oxides and occasionally to $\mathrm{Ca}-\mathrm{Fe}$ arsenates. The extraction procedures showed an opposite behavior of As and P; extracted P increased as As decreased in the samples affected by the effluent. Similarly, the P retention capacity decreased from $16 \%$ to $10-12 \%$ in the samples below the WWTP discharge, confirming the sequestration of wastewater-P in the sediment. The microprobe spot analyses $(\mathrm{n}=$ 162) of Fe (hydr)oxide grains agreed with the results obtained by extraction procedures and yielded lower As and higher $\mathrm{P}$ concentrations in the wastewater-affected samples. These results suggest that the wastewater-P co-precipitates with $\mathrm{Fe}$ (hydr)oxides and competes with As for sorption sites of $\mathrm{Fe}$ (hydr)oxides. A batch experiment was used to study the impact of low phosphate concentrations $(0 \mathrm{mM}-10 \mathrm{mM})$ on the mobility of As in sediments affected and unaffected by the WWTP effluent. This experiment showed that $10 \mathrm{mM}$ phosphate induced release of $0.3 \%$ of the total As (compared to extraction in deionized water) in the unaffected sediments. This phosphate level did not release As from affected sediments, and $100 \mathrm{mM}$ $\mathrm{PO}_{4}$ was needed for discernible As mobilization $(0.9 \%$ of the total As). These results suggest that As mobility will not increase in the wastewater-affected sediments if phosphate concentration in the stream does not exceed current levels $(4-81 \mathrm{mM})$. 